\title{
Social Determinants of Health: An Evaluation of Risk Factors Associated With Inpatient Presentations in the United States
}

\author{
Saanie Sulley ${ }^{1}$, Mathios Bayssie ${ }^{2}$ \\ 1. Health Informatics, National Healthy Start Association, Washington DC, USA 2. Emergency Medicine, Southern \\ Tennessee Regional Health System, Nashville, USA
}

Corresponding author: Saanie Sulley,ss2680@scarletmail.rutgers.edu

\begin{abstract}
Social Determinants of Health (SDoH) are socioeconomic indicators that directly or indirectly impact individual and community health outcomes. The distribution of most of these indicators within communities can be traced to public policies. These public policies often lead to diverse inequities with varying impacts on communities across the country. The inequities that arise because of specific public policies can be associated with increased risk factors and poor health outcomes among communities at high risk for these indicators. This study examined inpatient hospitalization and SDoH indicators that put individuals at risk of poor health outcomes. We utilized the National Inpatient Sample (NIS) databases 20122014 and 2016-2017 through the Healthcare Cost and Utilization Project (HCUP). The NIS datasets are deidentified to ensure patients' privacy. The HCUP-NIS dataset is a well-established sizable all-payer inpatient dataset for national estimates. It includes primary, secondary inpatient diagnoses as well as demographic information. SDoH indicators were identified using the International Classification of Diseases (ICD), versions 9 and 10 diagnosis codes. The relationship between SDoH indicators such as housing, psychosocial, healthcare access, upbringing, unemployment, social factors, gender, race, income, region, payer, age group, mortality, and severity was evaluated in a regression analysis. A total of 3,002,557 (2012-2014) and $1,254,899$ (2016-2017) cases were included in this study. Mental diseases $(\mathrm{p}<0.001)$ were high between 2012-2014 (OR 18.8, 95\% CI 18.20-19.42) and 2016-2017 (OR 4.11, 95\% CI 3.99-4.23). Native Americans had odds of presentation ( $\mathrm{p}<0.001$ ) with SDoH indicator between 2012-2014 (OR 1.15, 95\% CI 1.12-1.18) and 2016-2017 (OR 1.75, 95\% CI 1.70-1.79). The odds of presentation among long income group were high compared to other income categories ( $\mathrm{p}$ < 0.001) between 2012-2014 (OR 1.15, 95\% CI 1.15-1.16) and 20162017 (OR 1.26, 95\% CI 1.28-1.32). In conclusion, disparities, severity, and mortality risk at presentation were high among minority communities, males, and low-income demographics across all regions of United States
\end{abstract}

Review began 01/29/2021 Review ended 02/10/2021 Published 02/11/2021

\section{() Copyright 2021}

Sulley et al. This is an open access article distributed under the terms of the Creative Commons Attribution License CC-BY 4.0., which permits unrestricted use, distribution, and reproduction in any medium, provided the original author and source are credited.
Categories: Preventive Medicine, Public Health, Epidemiology/Public Health

Keywords: health care disparities, mental health comorbidities, psycho-behavioral, unemployment, culture and social determinants of health, $\bullet$ access to healthcare and health outcomes of vulnerable populations, housing difficulties, mental health literacy, healthcare inequality, race inequities

\section{Introduction}

Social Determinants of Health (SDoH) are essential indicators that directly or indirectly impact one's ability to effectively manage medical conditions and outcomes [1-3]. In recent years, there have been concerted efforts at the local and national levels to decrease the disparities that exist in healthcare outcomes through the healthy people initiative [4]. Given the variances in presentations, health outcomes among individuals meeting these SDoH classifications need careful evaluation to ensure practical and strategic approaches to addressing them $[5,6]$. These $\mathrm{SDoH}$ have been shown to disproportionally affect low-income and minority communities across the country [7-9]. These indicators could hold the key to identify the most vulnerable populations in communities and to target them for preventive interventions. Inpatient data is rarely utilized in understanding some of the factors that play a crucial role in patient presentations. Utilization of such data in combination with the outpatient and community service providers' data could provide a much better overview of the impact of such determinants on hospitalization and community resource allocation. Furthermore, it can tailor needed care to these populations based on specific needs [10]. This study evaluates the dynamics associated with socioeconomic and demographic factors impacting inpatient presentation of patients with SDoH indicators.

These valuable markers have been inadequately used to better coordinate care and improve community health outcomes. This study aims to provide an overview of how healthcare organizations and hospitals or direct care providers could inculcate SDoH indicators as part of their community health evaluation and assessment [11]. The level of care coordination and collaboration of such determinants could be the thriving force to improve outcomes, especially among the most vulnerable populations in our communities. Understanding the unique characteristics associated with these presentations could help targeted approaches to policy and strategic accountability to ensure equitable care approaches in communities across the country. 


\section{Cureus}

\section{Materials And Methods}

This retrospective analysis of inpatient hospitalization with SDoH was conducted using National Inpatient Sample (NIS) databases 2012-2014 and 2016-2017 available through the Healthcare Cost and Utilization Project (HCUP). The Agency for Healthcare Research and Quality (AHRQ) sponsors the HCUP databases. The NIS datasets are de-identified to ensure patients' privacy; providers and hospitals are also de-identified in the NIS datasets.

HCUP-NIS is a well-established sizable all-payer inpatient dataset for national estimates. The dataset includes primary and secondary inpatient diagnoses as well as demographic information. SDoH presentations were included if coded as primary or secondary diagnosis using International Classification of Diseases (ICD) 9/10 CM codes (Table 1). The SDoH indicators included are housing difficulties, family circumstances, psychosocial issues, healthcare access, unemployment, education and literacy, problems related to upbringing, as well as social and environmental factors. These indicators correspond to ICD-9 (V60-60) and ICD-10 (Z59-Z75). A total of 3,002,558 and 1,254,899 SDoH cases were identified between 2012-2014 and 2016-2017 in the NIS dataset, respectively.

\begin{tabular}{|c|c|c|}
\hline \multicolumn{3}{|l|}{ Study Sample Characteristics } \\
\hline Variables of Interest & $\mathrm{N}$ & \\
\hline Inclusion (N-weighted) & $\begin{array}{l}2012- \\
2014 \text { (\%) }\end{array}$ & $\begin{array}{l}2016- \\
2017 \text { (\%) }\end{array}$ \\
\hline $\begin{array}{l}\text { *Combined SDoH Indicator (Housing, Family, Psychosocial, Healthcare Access, Education, } \\
\text { Unemployment, Upbringing, Social Environment) }\end{array}$ & $\begin{array}{l}3,002,557 \\
(2.8)\end{array}$ & $\begin{array}{l}1,254,899 \\
(1.8)\end{array}$ \\
\hline Housing Difficulties & $726,313(20)$ & $774,022(55)$ \\
\hline Family Circumstances & $435,788(12)$ & $216,726(14)$ \\
\hline Psychosocial Issues & $\begin{array}{l}1,997,362 \\
(55)\end{array}$ & $139,323(9)$ \\
\hline Healthcare Access & $36,315(1)$ & $3,096(0.2)$ \\
\hline Unemployment & $290,525(8)$ & $201,245(13)$ \\
\hline Education and Literacy & $36,315(1)$ & $23,220(1.5)$ \\
\hline Upbringing & $10,894(0.3)$ & $278,647(18)$ \\
\hline Social Environment & 72631 (2) & $201,240(13)$ \\
\hline \multicolumn{3}{|l|}{ Gender } \\
\hline Female & $\begin{array}{l}1,416,364 \\
(47)\end{array}$ & $526,315(42)$ \\
\hline Male & $\begin{array}{l}1,585,669 \\
(53)\end{array}$ & $728,329(58)$ \\
\hline \multicolumn{3}{|l|}{ Race/Ethnicity } \\
\hline White & $\begin{array}{l}1,844,269 \\
(66)\end{array}$ & $745,684(59)$ \\
\hline Black & $508,700(18)$ & $248,620(20)$ \\
\hline Hispanic & $283,305(10)$ & $125,375(10)$ \\
\hline Asian or Pacific Islander & $37,505(1)$ & $16,610(1.3)$ \\
\hline Native American & $19,865(0.7)$ & $13,040(1)$ \\
\hline Other & $89,130(3)$ & $34,805(2.8)$ \\
\hline \multicolumn{3}{|l|}{ Payer } \\
\hline Medicare & $779,120(26)$ & $312,160(25)$ \\
\hline Medicaid & 995,989 (33) & $565,764(45)$ \\
\hline Private Insurance & $672,364(22)$ & $193,125(15)$ \\
\hline
\end{tabular}




\section{Cureus}

Self-Pay

334,815 (11) $\quad 112,910(9)$

No Charge

44,965 (2)

13,755 (1)

Other

$167,905(6) \quad 52,645(4)$

Census Division

New England

$192,800(6)$

$77,320(6.2)$

Middle Atlantic

448,420 (15)

168,870 (14)

East North Central

465,890 (16) $\quad 177,290(14)$

West North Central

266,049 (9) $\quad 95,375(8)$

South Atlantic

$617,780(21) \quad 245,370(20)$

East South Central

$159,530(5)$

$67,560(5)$

West South Central

$260,850(9) \quad 98,200(8)$

Mountain

$157,843(5) \quad 89,925(7)$

Pacific

433,395 (14) $\quad 234,989(19)$

Household Income

$<\$ 43,000$

$984,359(35)$

$434,995(38)$

$<\$ 54,000$

$746,764(26)$

291,485 (26)

$<\$ 71,000$

$620,649(22)$

$242,355(21)$

$\$ 71,000+$

486,770 (17) $\quad 174,740(15)$

Age Group (Years)

$<17$

253,454 (9)

$93,690(8)$

$18-24$

$323,090(11) \quad 103,650(8)$

25-34

534,505 (18) $\quad 205,650$ (16)

35-44

$491,205(17) \quad 198,020(16)$

45-54

$636,585(21)$

$254,280(20)$

55-64

391,520 (13) $\quad 217,110(17)$

$65+$

$354,510(12) \quad 168,620$ (13)

\section{TABLE 1: Study Sample Characteristics and Inclusion Summary}

${ }^{*}$ Records with missing cases were excluded from the analysis.

SDoH: Social Determinants of Health; ICD: International Classification of Diseases.

These data were further analyzed by the most frequent Major Diagnostic Category (MDC) presentation in the selected SDoH presentations. The relationship between $\mathrm{SDoH}$ presentations by race, gender, hospital division, age, income, severity, mortality risk, payer, length of stay (LOS), number of diagnoses (NDX), and disposition was examined in the regression analysis. Discharge weight (provided in the NIS database) was applied to all calculations to attain a national representative sample. Weighted descriptive statistics, multivariate logistic regression, was conducted for the relationship between the variables.

We used Statistical Package for Social Sciences (SPSS) version 23.0 (IBM Corp., Armonk, NY) to conduct a retrospective analysis of the HCUP-NIS database from 2012 to 2014 and 2016 to 2017. Records with missing data were excluded from all calculations. We also used Microsoft Excel (Microsoft Corporation, Redmond, WA) to calculate the rates and graph the statistics in this study. The 2015 NIS data were not included because of the United States switch to ICD-10 in 2015. 


\section{Cureus}

\section{Results}

A total of 3,002,557 (2012-2014) and 1,254,899 (2016-2017) cases with combined primary and secondary SDoH indicators were identified. Figure 1 shows a variation in the presentation by race when compared with the ICD-9/10. This variation could be associated with a lack of knowledge or utilization of SDoH codes. Table 1 provides the descriptive statistics and analysis for the varied demographic characteristics of the study sample.

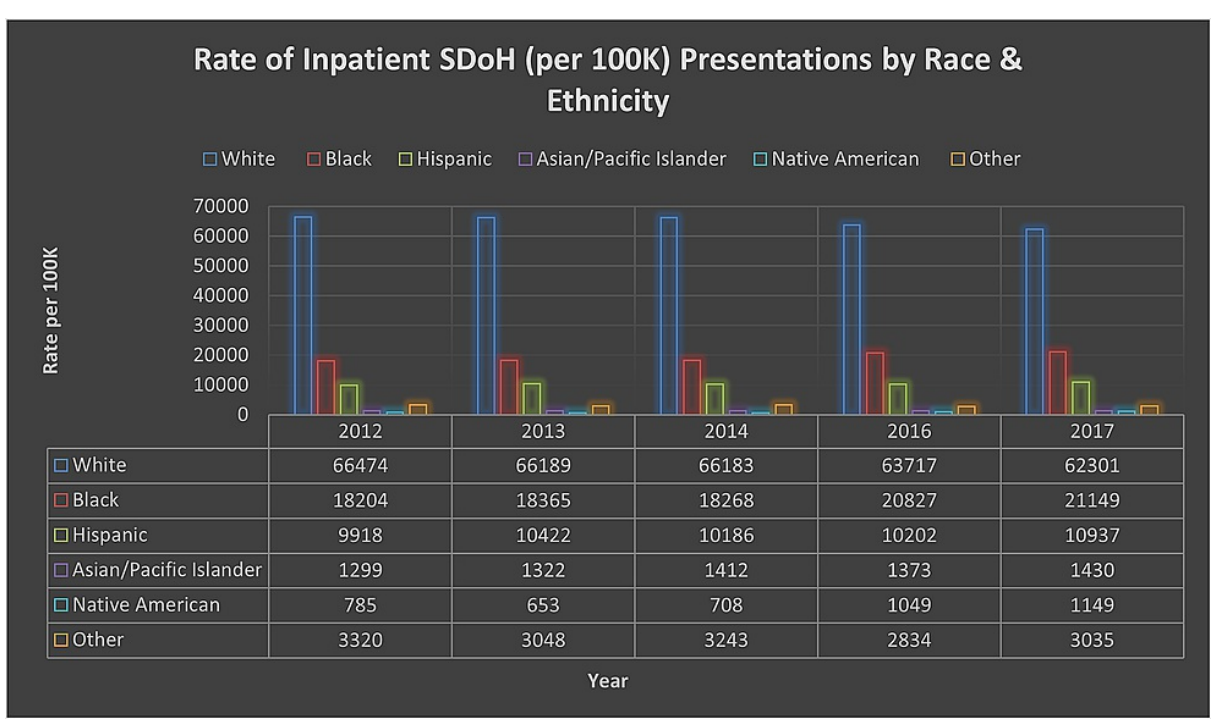

FIGURE 1: Rate of Inpatient SDoH (per 100K) Presentation by Race and Ethnicity

SDoH: Social Determinants of Health.

The odds of mental disease and disorders presentation were high between 2012-2014 (OR 18.8, 95\% CI 18.20-19.42) and 2016-2017 (OR 4.11, 95\% CI 3.99-4.23). The variation in presentation could be associated with several factors, including the utilization of codes. The relationship between SDoH indicator and alcohol and the drug-related presentation were significant $(\mathrm{p}<0.001$ ) between 2012-2014 (OR 5.02, 95\% CI 4.86-5.19) and 2016-2017 (OR 2.10, 95\% CI 2.04-2.16).

The population's racial and ethnic demographics show significance among all classification with individuals identified as White with OR 1.19 (95\% CI 1.18-1.20) between 2012 and 2014 and Other with OR 1.35 (95\% CI 1.28-1.32) between 2016 and 2017. This finding shows a variation in the patient population's presentation as shown in Figure 1 and Table 2. The likelihood of presentation among males varied slightly with OR 1.17 (95\% CI 1.17-1.18) and OR 1.30 (95\% CI 1.29-1.30) between 2012-2014 and 2016-2017. Both presentations were statistically significant $(\mathrm{p}<0.001)$.

\begin{tabular}{|c|c|c|c|c|c|c|}
\hline \multirow[b]{2}{*}{ Variables } & \multicolumn{2}{|c|}{ 2012-2014 } & \multicolumn{2}{|c|}{ 2016-2017 } & \multicolumn{2}{|c|}{ P value (Sig) } \\
\hline & OR & $95 \mathrm{Cl}$ & OR & $95 \mathrm{Cl}$ & $\begin{array}{l}2012- \\
2014\end{array}$ & $\begin{array}{l}2016- \\
2017\end{array}$ \\
\hline \multicolumn{7}{|l|}{ Disposition } \\
\hline Routine Discharge & 0.88 & $\begin{array}{l}0.81- \\
0.95\end{array}$ & 1.57 & $\begin{array}{l}1.23- \\
2.01\end{array}$ & 0.002 & $<0.001$ \\
\hline Transfer to Short-term Hosp & 0.79 & $\begin{array}{l}0.73- \\
0.85\end{array}$ & 1.44 & $\begin{array}{l}1.13- \\
1.84\end{array}$ & 0.003 & 0.003 \\
\hline Transfer Other: Includes Skilled Nursing Facility & 1.07 & $\begin{array}{l}0.99- \\
1.15\end{array}$ & 1.76 & $\begin{array}{l}1.38- \\
2.25\end{array}$ & 0.070 & 0.001 \\
\hline Home Health Care (HHC) & 0.57 & $\begin{array}{l}0.53- \\
0.62\end{array}$ & 0.92 & $\begin{array}{l}0.72- \\
1.18\end{array}$ & $<0.001$ & 0.535 \\
\hline Against Medical Advice & 1.17 & $\begin{array}{l}1.08- \\
1.26\end{array}$ & 2.8 & $\begin{array}{l}2.21- \\
3.61\end{array}$ & $<0.001$ & $<0.001$ \\
\hline
\end{tabular}




\section{Cureus}

*Discharged Alive

$<0.001$

Most Common Diagnoses (Major Diagnostic Category)

Mental Disease and Disorders

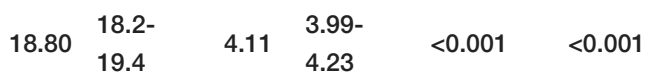

Alcohol and Drug Use

$\begin{array}{llll}5.02 & \begin{array}{l}4.86- \\ 5.19\end{array} & 2.04 & \begin{array}{l}2.04- \\ 2.16\end{array}\end{array} \quad<0.001 \quad<0.001$

Injuries, Poisonings, and Toxic Effects of Drugs

$\begin{array}{llll}1.68 & \begin{array}{l}1.62- \\ 1.73\end{array} & 0.79 & \begin{array}{l}0.76- \\ 0.81\end{array}\end{array} \quad<0.001 \quad<0.001$

Sex

${ }^{*}$ Female

Male

$\begin{array}{lllll}1.17 & 1.7-1.18 & 1.30 & \begin{array}{l}1.29- \\ 1.30\end{array} & <0.001\end{array}<0.001$

Race

*Other

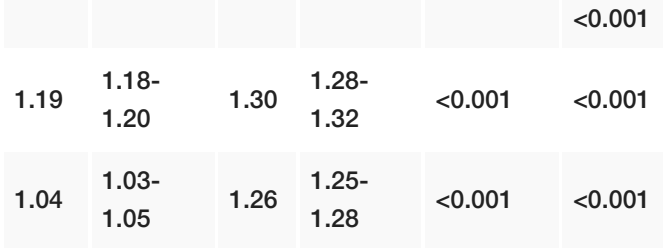

Hispanic

$\begin{array}{lllll}0.93 & \begin{array}{l}0.92- \\ 0.94\end{array} & 0.86 & \begin{array}{l}0.85- \\ 0.87\end{array} & <0.001\end{array} \quad<0.001$

Asian or Pacific Islander

$\begin{array}{llllll}0.72 & \begin{array}{l}0.70- \\ 0.72\end{array} & 0.71 & \begin{array}{l}0.70- \\ 0.73\end{array} & <0.001 & <0.001\end{array}$

Native American

$\begin{array}{llll}1.19 & \begin{array}{l}1.12- \\ 1.21\end{array} & 1.75 & \begin{array}{l}1.70- \\ 1.79\end{array}\end{array} \quad<0.001 \quad<0.001$

Census Region

New England

$\begin{array}{lllll}0.94 & 0.93- & 1.02 & 1.01- \\ 1.94 & 1.03 & <0.001 & <0.001\end{array}$

Middle Atlantic

$\begin{array}{llll}0.59 & \begin{array}{l}0.59- \\ 0.60\end{array} & 0.64 & \begin{array}{l}0.63- \\ 0.64\end{array}\end{array} \quad<0.001 \quad<0.001$

East North Central

$\begin{array}{llllll}0.69 & \begin{array}{l}0.68- \\ 0.69\end{array} & 0.66 & \begin{array}{l}0.66- \\ 0.67\end{array} & <0.001 & <0.001\end{array}$

West North Central

$\begin{array}{llllll}0.78 & \begin{array}{l}0.77- \\ 0.79\end{array} & 0.65 & \begin{array}{l}0.65- \\ 0.66\end{array} & 0.126 & <0.001\end{array}$

South Atlantic

$0.73 \begin{array}{llll}0.72- \\ 0.74\end{array} \quad 0.68 \begin{aligned} & 0.68- \\ & 0.69\end{aligned} \quad<.001 \quad<0.001$

East South Central

$\begin{array}{llllll}0.63 & \begin{array}{l}0.62- \\ 0.64\end{array} & 0.57 & \begin{array}{l}0.57- \\ 0.58\end{array} & <0.001 & <0.001\end{array}$

West South Central

$\begin{array}{llll}0.65 & \begin{array}{l}0.65- \\ 0.66\end{array} & 0.59 & \begin{array}{l}0.59- \\ 0.60\end{array}\end{array} \quad<0.001 \quad<0.001$

Mountain

$\begin{array}{lllll}0.80 & 0.80- & 0.95 & \begin{array}{l}0.94- \\ 0.96\end{array} & <0.001\end{array}<0.001$

${ }^{\star}$ Pacific

$<0.001<0.001$

Primary Payer

Medicare

$\begin{array}{lllll}0.53 & 0.53- & 0.52 & 0.51- \\ 0.54 & 0.52\end{array} \quad<0.001 \quad<0.001$

Medicaid

$\begin{array}{llllll}1.13 & \begin{array}{l}1.12- \\ 1.14\end{array} & 1.34 & \begin{array}{l}1.30- \\ 1.32\end{array} & <0.001 & <0.001\end{array}$ 


\section{Cureus}

\begin{tabular}{|c|c|c|c|c|c|c|}
\hline Private Insurance & 0.70 & $\begin{array}{l}0.69- \\
0.71\end{array}$ & 0.51 & $\begin{array}{l}0.50- \\
0.51\end{array}$ & $<0.001$ & $<0.001$ \\
\hline Self-Pay & 1.37 & $\begin{array}{l}1.36- \\
1.39\end{array}$ & 1.47 & $\begin{array}{l}1.46- \\
1.49\end{array}$ & $<0.001$ & $<0.001$ \\
\hline No Charge & 1.16 & $\begin{array}{l}1.58- \\
1.64\end{array}$ & 1.79 & $\begin{array}{l}1.75- \\
1.83\end{array}$ & $<0.001$ & $<0.001$ \\
\hline *Other & & & & & $<0.001$ & $<0.001$ \\
\hline \multicolumn{7}{|l|}{ Rural-Urban Code } \\
\hline "Central" Counties of Metro Areas of $\geq 1$ Million Population & 1.30 & $\begin{array}{l}1.29- \\
1.31\end{array}$ & 1.41 & $\begin{array}{l}1.40- \\
1.42\end{array}$ & $<0.001$ & $<0.001$ \\
\hline "Fringe" Counties of Metro Areas of $\geq 1$ Million Population & 1.19 & $\begin{array}{l}1.18- \\
1.20\end{array}$ & 1.21 & $\begin{array}{l}1.20- \\
1.23\end{array}$ & $<0.001$ & $<0.001$ \\
\hline Counties in Metro Areas of $250,000-999,999$ Population & 1.32 & $\begin{array}{l}1.30- \\
1.33\end{array}$ & 1.35 & $\begin{array}{l}1.33- \\
1.36\end{array}$ & $<0.001$ & $<0.001$ \\
\hline Counties in Metro Areas of 50,000-249,999 Population & 1.31 & $\begin{array}{l}1.30- \\
1.33\end{array}$ & 1.37 & $\begin{array}{l}1.35- \\
1.38\end{array}$ & $<0.001$ & $<0.001$ \\
\hline Micropolitan Counties & 1.20 & $\begin{array}{l}1.95- \\
1.21\end{array}$ & 1.11 & $\begin{array}{l}1.09- \\
1.12\end{array}$ & $<0.001$ & $<0.001$ \\
\hline “Not Metropolitan or Micropolitan Counties & & & & & $<0.001$ & 0.005 \\
\hline \multicolumn{7}{|l|}{ Median Household Income } \\
\hline$<\$ 43,000$ & 1.15 & $\begin{array}{l}1.15- \\
1.16\end{array}$ & 1.26 & $\begin{array}{l}1.28- \\
1.32\end{array}$ & $<0.001$ & \\
\hline$<\$ 54,000$ & 1.07 & $\begin{array}{l}1.06- \\
1.08\end{array}$ & 1.10 & $\begin{array}{l}1.10- \\
1.11\end{array}$ & $<0.001$ & 0.001 \\
\hline$<\$ 71,000$ & 1.02 & $\begin{array}{l}1.02- \\
1.03\end{array}$ & 1.06 & $\begin{array}{l}1.05- \\
1.06\end{array}$ & $<0.001$ & $<0.001$ \\
\hline *\$71,000+ & & & & & $<0.001$ & $<0.001$ \\
\hline \multicolumn{7}{|l|}{ Severity Risk } \\
\hline $\begin{array}{l}\text { Minor Loss of Function (Includes Cases With No Comorbidity or } \\
\text { Complications) }\end{array}$ & 0.64 & $\begin{array}{l}0.63- \\
0.65\end{array}$ & 0.54 & $\begin{array}{l}0.54- \\
0.55\end{array}$ & 0.001 & $<0.001$ \\
\hline Moderate Loss of Function & 0.86 & $\begin{array}{l}0.85- \\
0.87\end{array}$ & 0.90 & $\begin{array}{l}0.89- \\
0.92\end{array}$ & $<0.001$ & $<0.001$ \\
\hline Major Loss of Function & 1.00 & $\begin{array}{l}0.98- \\
1.01\end{array}$ & 1.15 & $\begin{array}{l}1.13- \\
1.16\end{array}$ & 0.867 & $<0.001$ \\
\hline${ }^{\star}$ Extreme Loss of Function & & & & & $<0.001$ & $<0.001$ \\
\hline \multicolumn{7}{|l|}{ Mortality Risk (\%) } \\
\hline \multicolumn{7}{|l|}{ ”Did Not Die } \\
\hline Died & 1.75 & $\begin{array}{l}1.61- \\
1.89\end{array}$ & 1.09 & $\begin{array}{l}0.85- \\
1.39\end{array}$ & $<0.001$ & 0.500 \\
\hline No Class Specified & 0.69 & $\begin{array}{l}0.55- \\
0.88\end{array}$ & 1.67 & $\begin{array}{l}1.41- \\
1.99\end{array}$ & $<0.003$ & $<0.001$ \\
\hline Minor Likelihood of Dying & 1.53 & $\begin{array}{l}1.50- \\
1.55\end{array}$ & 1.80 & $\begin{array}{l}1.77- \\
1.83\end{array}$ & $<0.001$ & $<0.001$ \\
\hline Moderate Likelihood of Dying & 1.53 & $\begin{array}{l}1.51- \\
1.56\end{array}$ & 1.49 & $\begin{array}{l}1.46- \\
1.53\end{array}$ & $<0.001$ & $<0.001$ \\
\hline Major Likelihood of Dying & 1.14 & $\begin{array}{l}1.12- \\
1.15\end{array}$ & 1.13 & $\begin{array}{l}1.11- \\
1.15\end{array}$ & $<0.001$ & $<0.001$ \\
\hline
\end{tabular}




\section{Cureus}

\section{TABLE 2: Logistic Regression Analysis for SDoH Cases (2012-2014 and 2016-2017)}

*Reference.

SDoH: Social Determinants of Health.

Emergency department (ED) presentations were significant $(\mathrm{p}<0.001)$ for SDoH indicators with OR 1.10 (95\% CI 1.09-1.11) between 2012 and 2014 and OR 0.91(95\% CI 0.90-0.92) between 2016 and 2017. A significant relationship was observed in all regions with an increased odd of presentation in New England between 2012-2014 (OR 0.94, 95\% CI 0.93-0.94) and 2016-2017 (OR 1.02, 95\% CI 1.01-1.04). The mortality rate among individuals with SDoH indicator was significant $(\mathrm{p}<0.001)$ with an OR of 1.75 (95\% CI 1.61-1.89) from 2012 to 2014.

Further analysis shows a significant relationship between patient's discharge against medical advice and the presence of most of the SDoH indicators included in this study. Payer demographics shows significance ( $\mathrm{p}$ 0.001) among individuals without insurance (No Charge) between 2012-2014 (OR 1.61, 95\% CI 1.58-1.64) and 2016-2017 (OR 1.79, 95\% CI 1.75-1.83). A significant presentation was observed across the country based on rural-urban classification, as indicated in Table 2. The odds of presentation based on the lowest income group were statistically significant with $\mathrm{p}<0.001$ between 2012-2014 (OR 1.16, 95\% CI 1.15-1.16) and 2016-2017 (OR 1.26, 95\% CI 1.25-1.27). Figure 2 provides an overview of income demographics in the population. Inpatient presentation by region (Figure 3) with the North East among SDoH cases was significant, $\mathrm{p}<0.001$ (OR 1.02, 95\% CI 1.01-1.03).

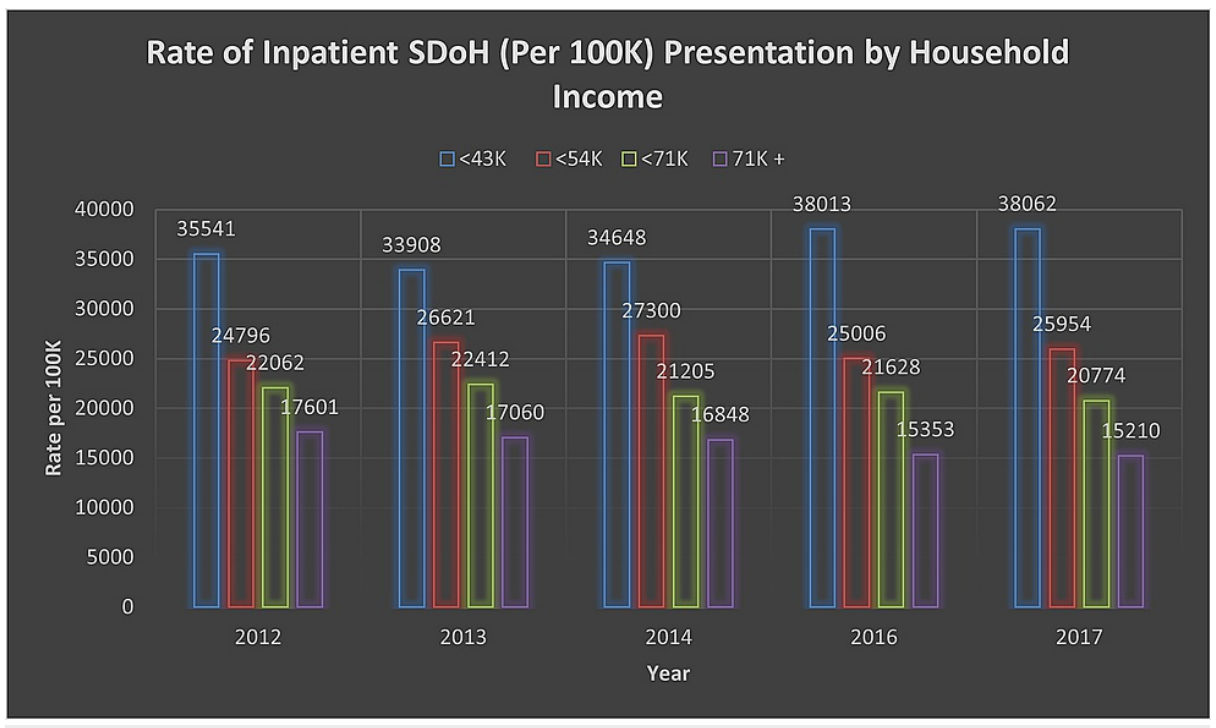

FIGURE 2: Rate of Inpatient SDoH (per 100K) Presentation by Household Income

SDoH: Social Determinants of Health. 


\section{Cureus}

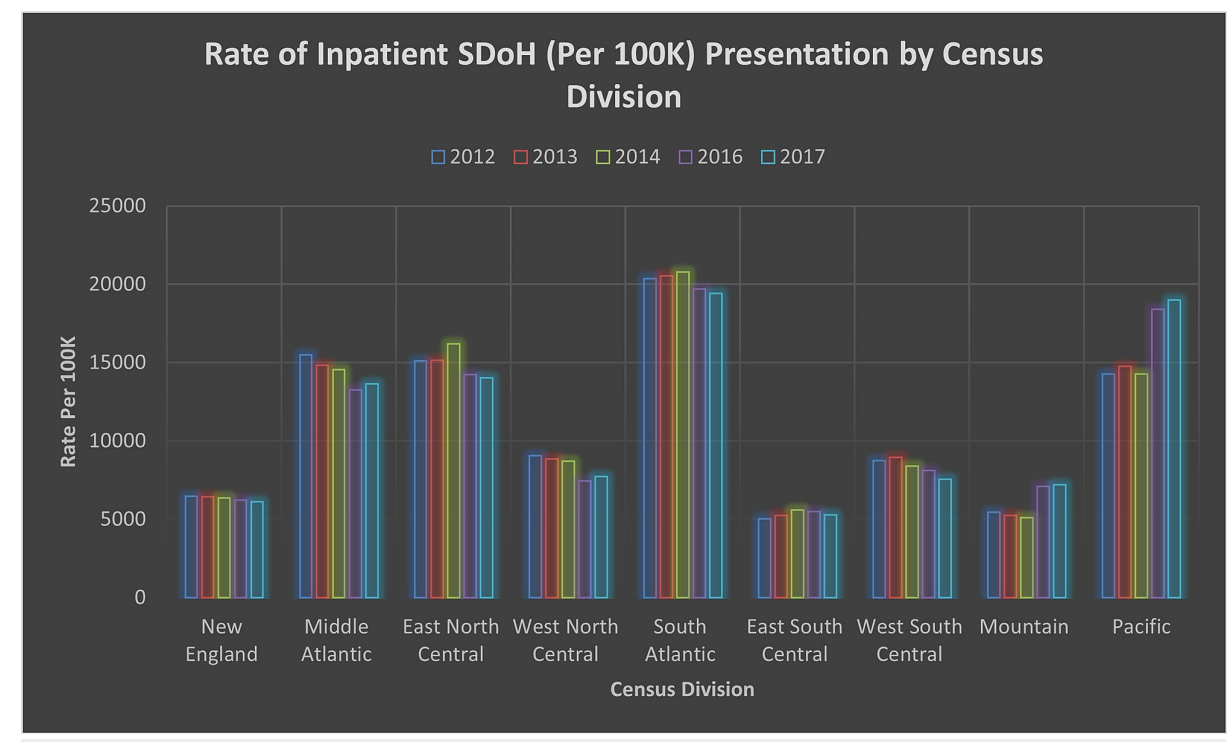

\section{FIGURE 3: Rate of Inpatient SDoH (Per 100K) Presentation by Census Division}

SDoH: Social Determinants of Health.

New England: Maine, New Hampshire, Vermont, Massachusetts, Rhode Island, and Connecticut.

Mid-Atlantic: New York, Pennsylvania, and New Jersey.

East North Central: Wisconsin, Michigan, Illinois, Indiana, and Ohio.

West North Central: Missouri, North Dakota, South Dakota, Nebraska, Kansas, Minnesota, and lowa.

South Atlantic: Delaware, Maryland, District of Columbia, Virginia, West Virginia, North Carolina, South Carolina, Georgia, and Florida.

East South Central: Kentucky, Tennessee, Mississippi, and Alabama.

West South Central: Oklahoma, Texas, Arkansas, and Louisiana.

Mountain: Idaho, Montana, Wyoming, Nevada, Utah, Colorado, Arizona, and New Mexico.

Pacific: Alaska, Washington, Oregon, California, and Hawaii.

\section{Discussion}

The SDoH presentation trend in each subcategory shows an increase when comparing ICD-9 (2012-2014) and ICD-10 (2016-2017). The reduction in actual case presentation may be associated with the switch from ICD-9 to ICD-10 and more specificity in the classification of these determinants, as shown in Figure 1. In recent years, efforts to capture SDoH in EHR systems have increased and could also be one of the many reasons for less utilization of the ICD codes. Psychosocial, housing difficulties, and unemployment make up the highest percentage in presentation among the population. These findings are consistent with other published literature regarding the prevalence of social determinants of health [12-14].

This study shows consistent high odds of presentation for mental and behavioral health among this population. This further highlights the need for more focus and investment in mental and behavioral health to mitigate disproportionate health outcomes among these populations [15-18]. Such investment in mental and behavioral health is even more timely, given the increase in the rate of SDoH in all communities across the country because of the COVID-19 pandemic. The current approaches to care need to be reevaluated $[19,20]$ to focus more on co-operation [18] and to create an effective referral system to ensure populations needing social services have access to such services in tandem with their medical needs. Community-based mental health services and approaches also need to be adopted and implemented to improve health outcomes [21].

This study demonstrates that Native Americans are consistently at higher odds of having SDoH classification than other race or ethnic demographics in the United States. The significant severity and mortality risk at 
presentation was also consistently high among Native Americans, Asian/Pacific Islander, and Black between 2012-2014 and 2016-2017. It shows that the increased risk of disease severity and mortality in minority communities is associated with a higher risk of negative SDoH. A review of severity and mortality risks at a presentation by household income as a SDoH indicator shows consistently higher moderate risks among lower income and many minority populations between 2012-2014 and 2016-2017. Such findings are consistent with other studies that have found higher stressors among low-income and minority communities [16,22-25]. These findings call for a re-evaluation of public policy on social and economic inequalities and support models focusing on minority populations to mitigate poor SDoH.

The highest percentage age distribution at presentation was $45-54$ years (20\%); $12.5 \%$ of the study population in the data were above 65 years of age. The number of older adults meeting these criteria seems to be increasing, as shown in Table 1 . As age increased, the risk of significant severity and mortality at presentation increased across all country census divisions. The consistent utilization rate of Medicaid and Medicare as primary coverage further supports the need for a multistakeholder approach to addressing SDoH in communities, especially among the elderly living in communities. This finding also shows that local governments and policymakers are an indispensable part of a strategy for addressing social factors impacting health outcomes $[14,26]$. Decisions on resource allocation, job programs, subsidized/affordable housing can improve health outcomes, and policymakers are at the forefront of implementing such changes affecting SDoH.

Development and implementation of community engagement strategies focused on addressing these social factors impacting health could pave the way for improving health outcomes. Tailoring programs based on community needs, evidence, and key performance indicators could help develop public, private, and community collaboratives to address social factors impacting health outcomes. The use of ICD codes alone may not be the most effective strategy in understanding these presentations' social dynamics. A combination of ICD codes and EHR data could provide a better understanding of these presentations. It could also serve as an avenue to improve the quality of data collected in an inpatient setting. The use of technology in referral processes could also hold the key to collaboration between inpatient, outpatient, and social service providers. Studies have found that even though there is an increase in health system investment in areas associated with improving SDoH, these investments only make up a small fraction of total healthcare expenditure [27,28]. Given the transient nature of some of these SDoH [29], it is imperative to address them effectively to limit exacerbating medical conditions and worsening population health indicators. Collaboration between all service providers is essential to manage SDoH issues affecting health outcomes in diverse communities.

This retrospective study cannot conclude causation. It provides an overview of SDoH code utilization/presentation in inpatient settings across the United States between 2012-2014 (ICD-9) and 20162017 (ICD-10). It further provides insights into how inpatient service providers could inculcate SDoH codes in developing comprehensive community health needs assessments. Such an approach could help all community stakeholders develop adequate data-driven policy and implementation strategies to improve health outcomes among individuals with SDoH risk factors.

\section{Limitations}

The utilization of multiple versions of ICD may have impacted the inclusion criteria. The use and adoption of new codes, especially when they are not reimbursable, may have affected the number of cases for both ICD-9 and ICD-10. Increasing the use of other EHR system features could be a limiting factor in capturing SDoH through ICD code. A combination of ICD codes and EHR data in analyzing SDoH would provide a more comprehensive overview of these indicators.

\section{Conclusions}

SDoH are significant risk factors for lowered health outcomes for minority populations. Many SDoH can be addressed during outpatient visits with practical preventive care approaches tailored toward addressing these risk factors based on local community dynamics. High risk among low-income earners, minority racial groups, and public payer groups in most regions indicates a need for focused collaborative approaches to improving health outcomes through active community-based partnerships to address social needs.

\section{Appendices}




\section{Cureus}

\begin{tabular}{|c|c|c|}
\hline SDoH Indicator & ICD-9 Code & ICD-10 Code \\
\hline Housing Difficulties & V60.XX & $Z 59 . X X$ \\
\hline Family Circumstances & $\mathrm{V} 61.03, \mathrm{~V} 61.49, \mathrm{~V} 61.8, \mathrm{~V} 61.9$ & Z63.XX \\
\hline Psychosocial Issues & V61.5, V61.6, V61.7, V62.81 & Z64.XX \\
\hline Healthcare Access & V63.8, V63.9 & Z75.X \\
\hline Unemployment & V62.XX & Z56.XX \\
\hline Education and Literacy & V62.3 & Z55.XX \\
\hline Upbringing & V61.XX & Z62.XX \\
\hline Social Environment & V62.89, V60.3, V62.4 & Z60.XX \\
\hline
\end{tabular}

\section{TABLE 3: ICD-9/10 Codes Inclusion Criteria}

ICD: International Classification of Diseases; SDoH: Social Determinants of Health.

\section{Additional Information Disclosures}

Human subjects: All authors have confirmed that this study did not involve human participants or tissue. Animal subjects: All authors have confirmed that this study did not involve animal subjects or tissue. Conflicts of interest: In compliance with the ICMJE uniform disclosure form, all authors declare the following: Payment/services info: All authors have declared that no financial support was received from any organization for the submitted work. Financial relationships: All authors have declared that they have no financial relationships at present or within the previous three years with any organizations that might have an interest in the submitted work. Other relationships: All authors have declared that there are no other relationships or activities that could appear to have influenced the submitted work.

\section{References}

1. About Social Determinants of Health (SDOH). (2020). Accessed: December 5, 2021: https://www.cdc.gov/socialdeterminants/about.html.

2. Metzler M: Social determinants of health: what, how, why, and now . Prev Chronic Dis. 2007, 4:A85.

3. Bambra C, Gibson M, Sowden A, Wright K, Whitehead M, Petticrew M: Tackling the wider social determinants of health and health inequalities: evidence from systematic reviews. J Epidemiol Community Health. 2010, 64:284-91. 10.1136/jech.2008.082743

4. Social Determinants of Health. (2020). Accessed: November 8, 2020: https://www.healthypeople.gov/2020/topics-objectives/topic/social-determinants-of-health.

5. Cheng JK: Confronting the social determinants of health - obesity, neglect, and inequity . N Engl J Med. 2012, 367:1976-1977. 10.1056/NEJMp1209420

6. Butkus R, Rapp K, Cooney TG, Engel LS, Health and Public Policy Committee of the American College of Physicians: Envisioning a better U.S. health care system for all: reducing barriers to care and addressing social determinants of health. Ann Intern Med. 2020, 172:S50-S59. 10.7326/M19-2410

7. Kawachi I, Daniels N, Robinson DE: Health disparities by race and class: why both matter . Health Aff (Millwood). 2005, 24:343-52. 10.1377/hlthaff.24.2.343

8. Betancourt JR, Green AR, Carrillo JE, Park ER: Cultural competence and health care disparities: key perspectives and trends. Health Aff (Millwood). 2005, 24:499-505. 10.1377/hlthaff.24.2.499

9. Gehlert S, Sohmer D, Sacks T, Mininger C, McClintock M, Olopade O: Targeting health disparities: a model linking upstream determinants to downstream interventions. Health Aff (Millwood). 2008, 27:339-49. 10.1377/hlthaff.27.2.339

10. Luck J, Chang C, Brown ER, Lumpkin J: Using local health information to promote public health. Health Aff (Millwood). 2006, 25:979-91. 10.1377/hlthaff.25.4.979

11. Umberson D, Montez JK: Social relationships and health: a flashpoint for health policy . J Health Soc Behav. 2010, 51:S54-S66. doi:10.1177/0022146510383501

12. Martikainen P, Bartley M, Lahelma E: Psychosocial determinants of health in social epidemiology . Int J Epidemiol. 2002, 31:1091-3. 10.1093/ije/31.6.1091

13. Krieger J, Higgins DL: Housing and health: time again for public health action . Am J Public Health. 2002, 92:758-68. 10.2105/ajph.92.5.758

14. Viner RM, Ozer EM, Denny S, Marmot M, Resnick M, Fatusi A, Currie C: Adolescence and the social determinants of health. Lancet. 2012, 379:1641-52. 10.1016/S0140-6736(12)60149-4

15. Linn MW, Sandifer R, Stein S: Effects of unemployment on mental and physical health. Am J Public Health. 1985, 75:502-6. 10.2105/ajph.75.5.502

16. Marmot M: Social determinants of health inequalities. Lancet. 2005, 365:1099-104. 10.1016/S0140- 
6736(05)71146-6

17. Lake J, Turner MS: Urgent need for improved mental health care and a more collaborative model of care . Perm J. 2017, 21:17-024. 10.7812/TPP/17-024

18. Braveman P, Gottlieb L: The social determinants of health: it's time to consider the causes of the causes Public Health Rep. 2014, 129:17-024. 10.1177/00333549141291S206

19. Galea S, Vlahov D: Social determinants and the health of drug users: socioeconomic status, homelessness, and incarceration. Public Health Rep. 2002, 117:S135-S145.

20. Wang PS, Lane M, Olfson M, Pincus HA, Wells KB, Kessler RC: Twelve-month use of mental health services in the United States: results from the national comorbidity survey replication. Arch Gen Psychiatry. 2005, 62:629-40. 10.1001/archpsyc.62.6.629

21. Sanders-Phillips K, Settles-Reaves B, Walker D, Brownlow J: Social inequality and racial discrimination: risk factors for health disparities in children of color. Pediatrics. 2009, 124:S176-86. 10.1542/peds.2009-1100E

22. Mongelli F, Georgakopoulos P, Pato MT: Challenges and opportunities to meet the mental health needs of underserved and disenfranchised populations in the United States. Focus (Am Psychiatr Publ). 2020, 18:1624. 10.1176/appi.focus.20190028

23. Jack L, Jack NH, Hayes SC: Social determinants of health in minority populations: a call for multidisciplinary approaches to eliminate diabetes-related health disparities. Diabetes Spectr. 2012, 25:13-9. 10.2337/diaspect.25.1.9

24. Morales LS, Lara M, Kington RS, Valdez RO, Escarce JJ: Socioeconomic, cultural, and behavioral factors affecting Hispanic health outcomes. J Health Care Poor Underserved. 2002, 13:477-503.

25. Egede LE: Race, ethnicity, culture, and disparities in health care. J Gen Intern Med. 2006, 21:667-69. 10.1111/j.1525-1497.2006.0512.x

26. Horwitz LI, Chang C, Arcilla HN, Knickman JR: Quantifying health systems' investment in social determinants of health, by sector, 2017-19. Health Aff (Millwood). 2020, 39:192-98. 10.1377/hlthaff.2019.01246

27. Altman DE, Morgan DH: The role of state and local government in health. Health Aff (Millwood). 1983, 2:731. 10.1377/hlthaff.2.4.7

28. Fiset-Laniel J, Guyon A, Perreault R, Strumpf EC: Public health investments: neglect or wilful omission? Historical trends in Quebec and implications for Canada. Can J Public Health. 2020, 111:383-388. 10.17269/s41997-020-00342-1

29. Feller DJ, Zucker J, Walk OBD, Yin MT, Gordon P, Elhadad N: Longitudinal analysis of social and behavioral determinants of health in the EHR: exploring the impact of patient trajectories and documentation practices. AMIA Annu Symp Proc. 2019, 2019:399-407. 